INT. J. REMOTE SENSING, 1999, VOL. 20, NO. 15 \& 16, 3111-3123

\title{
Retrieval of Antarctic sea-ice pressure ridge frequencies from ERS SAR imagery by means of in situ laser profiling and usage of a neural network
}

\author{
C. HAAS, Q. LIU†, T. MARTIN\$ \\ Alfred Wegener Institute for Polar and Marine Research, Columbusstrasse, \\ D-27568 Bremerhaven, Germany; \\ e-mail: chaas@awi-bremerhaven.de
}

\begin{abstract}
Application of a neural network to ERS-SAR images to retrieve pressure ridge spatial frequencies is presented. For an independent dataset, the rmserror between the retrieved and the true ridge frequency as determined by means of laser profiling was about 5 ridges per kilometre, or 30\%. The network is trained with results from in situ laser profiling of ridge distributions and coincident SAR backscatter properties. The study focuses on summer data from the Bellingshausen, Amundsen and Weddell Seas in Antarctica, which were gathered in February 1994 and 1997. Pressure ridge frequencies varied from 3 to 30 ridges per kilometre between different regions, thus providing a wide range of training and test data for the algorithm development.

From ERS-SAR images covering the area of the laser flights with a time difference of a few days at maximum, histograms of the backscatter coefficient $\sigma_{0}$ were extracted. Statistical parameters (e.g. mean, standard deviation, tail-to-mean ratio) were calculated from these distributions and compared with the results of the laser flights. Generally, the mean backscatter increases with a growing ridge frequency, and the signal range becomes narrower. However, these correlations are only poor, and improved results are obtained when the statistical parameters are combined to train the neural network.
\end{abstract}

\section{Introduction}

Convergent sea-ice motion frequently leads to the formation of pressure ridges. These are obvious as elevations above the ice surface, with heights of up to several metres and widths of up to some 10 metres. They can form lines of a few to several 100 metres. The magnitude of ice deformation, and thus the spatial frequency and height of ridges depends primarily on the atmospheric and ocean surface stresses. Numerical sea ice models which are designed to simulate sea ice deformation (e.g. Harder and Lemke 1994, Steiner et al. in press) need data on pressure ridge distributions for model validation and improvements.

\footnotetext{
†Current address: Institute for Marine Research, Düsternbrooker Weg 20, D-24105Kiel, Germany.

tCurrent address: NPOESS Raytheon STX, 4400 Forbes Blvd, USA-Lanham, MD 20706, USA.

Paper presented at the Fifth Circumpolar Remote Sensing Symposium held at the University of Dundee, Scotland, 22-25 June 1998.
} 
Since pressure ridges also affect shipping and other human activities in the polar regions, a reliable knowledge of their actual spatial distribution can be very useful. Adequate observations could best be obtained by means of radar satellite remote sensing, which cover at relatively short time intervals all sea ice areas. However, for this purpose an algorithm for a satisfactory interpretation of the satellite data is still required.

Subsequently, we propose a retrieval algorithm of pressure ridge spatial frequencies from ERS (European Remote-Sensing Satellite) -SAR (Synthetic Aperture Radar) images for Antarctic sea ice in summer. The data were acquired in February 1994 over the Bellingshausen and Amundsen Seas and in February 1997 over the Weddell Sea. The algorithm was developed with the aid of extensive helicopter laser profiling flights during periods of the SAR measurements and of a neural network.

\subsection{Detectability of pressure ridges in SAR images}

Generally, due to enhanced weathering, the ice of pressure ridges has a lower salinity and density and thus a higher porosity than the surrounding level ice (e.g. Tucker et al. 1992, Onstott 1992). Therefore the backscatter signal of ridges is enhanced by increased volume scattering (Carlström and Ulander 1995). More importantly, some surface facets of the piled ice blocks are oriented towards the incident radar rays, thus reducing the local incidence angles (e.g. Johansson and Askne 1987, Manninen 1996). Consequently, the backscatter energy of ridges is distinctly larger than that of level ice and so they can be clearly detected in SAR signals.

Similä et al. (1992) compared statistical properties of airborne SAR intensity distributions with ice morphology values from helicopter laser profiling. They found that the tail-to-mean ratio (see $\$ 2.2$ for definition) correlated well with the ridging intensity. Here, we make a similar approach for the satellite data. However, rather than correlating only one statistical parameter of the backscatter distribution with the corresponding laser data we utilize several parameters at once to train the neural network.

\subsection{SAR studies of Antarctic sea ice}

ERS-SAR studies of Antarctic summer sea ice have been performed by, for example, Low (1995), Drinkwater and Lytle (1997), Drinkwater (1998), and Morris et al. (1998). One of the findings is that backscatter coefficients are generally higher by as much as $2-5 \mathrm{~dB}$ in summer than in winter. Therefore algorithms developed for summer conditions are not applicable to winter measurements. Our study period in 1994 (29 January to 22 February, see table 1) fell well within the period of stable summer backscatter characteristics as shown by Morris et al. (1998). Similar conditions prevailed during the period in 1997.

In the Weddell Sea under non-melting conditions, Drinkwater (1998) distinguishes between regions with and without second-year ice, since the backscatter of second-year ice is much greater than that of first-year ice. Similarly, Morris et al. (1998) subdivide the Bellingshausen Sea into the coastal zone with first-year ice and the outer pack ice zone with perennial ice. Neither Drinkwater (1998) nor Morris et al. (1998) paid much attention to ridging and surface roughness although floes with a higher degree of deformation definitely produce a stronger backscatter. Here, we shall use particularly this latter effect in our subsequent consideration. 
Table 1. List of coincident SAR images and laser flights used in this study. DOY (Day-ofYear) is the date of the respective measurement.

\begin{tabular}{|c|c|c|c|c|c|}
\hline No. & Orbit & Frame & $\begin{array}{c}\text { DOY of SAR } \\
\text { image acquisition }\end{array}$ & $\begin{array}{l}\text { DOY of } \\
\text { laser flight }\end{array}$ & $\begin{array}{l}\text { Total length of } \\
\text { laser flight }(\mathrm{km})\end{array}$ \\
\hline \multicolumn{6}{|c|}{ 1994, Bellingshausen- and Amundsen Sea, ERS1 } \\
\hline BA1 & 13281 & 5031 & 029 & 029 & 54 \\
\hline BA2 & 13377 & $5697 / 5715$ & 036 & 036 & 43 \\
\hline $\mathrm{BA} 3$ & 13453 & 5103 & 041 & 041 & 21 \\
\hline BA4 & 13492 & 5697 & 044 & 044 & 60 \\
\hline BA5 & 13492 & 5733 & 044 & 045 & 63 \\
\hline BA6 & 13535 & 5715 & 047 & 048 & 54 \\
\hline BA7 & 13625 & 5103 & 053 & 053 & 37 \\
\hline BA8 & 13625 & 5121 & 053 & 055 & 7 \\
\hline \multicolumn{6}{|c|}{ 1997, Weddell Sea, ERS2 } \\
\hline W1 & 9351 & 5193 & 033 & 020 & 108 \\
\hline W2 & 9305 & 5625 & 030 & 027 & 79 \\
\hline W3 & 9596 & 5013 & 050 & 047 & 44 \\
\hline W4 & 9539 & 4977 & 046 & 050 & 103 \\
\hline W5 & 9610 & 5031 & 051 & 053 & 105 \\
\hline W6 & 9738 & 5139 & 060 & 058 & 100 \\
\hline
\end{tabular}

\section{Methods and measurements}

\subsection{Laser profiling}

Laser profiler measurements were performed during two cruises of RV Polarstern in January-February 1994 in the Bellingshausen and Amundsen Seas and in JanuaryFebruary 1997 in the Weddell Sea. The investigations also comprised ice coring and snow analyses as well as snow and ice thickness measurements (Haas et al. 1996, 1998, Haas 1998).

The timing and location of laser flights was chosen to coincide closely with SAR overflights. Thus, eight flights could be performed in the Bellingshausen and Amundsen Seas and six flights in the Weddell Sea (figure 1, table 1). In the latter area the laser and the satellite measurements differed by between 2 and 13 days. In total, profiles totalling $339 \mathrm{~km}$ in length were obtained in 1994 and $539 \mathrm{~km}$ in 1997. In 1994, the flight tracks were designed to form stars with six legs of 5 nautical miles in length, intersecting each other at an angle of $60^{\circ}$. In 1997 , equilateral triangles with a side length of 20 nautical miles were flown. We are confident that the lengths of the profiles are sufficient to yield representative ridge statistics for each region (table 1).

Laser measurements were performed with an IBEO PS100EL laser distance meter operating at a pulse wavelength of $905 \mathrm{~nm}$. The accuracy is about $\pm 3 \mathrm{~cm}$. The laser was mounted on a helicopter to measure the altitude above the ice surface which nominally was $30 \mathrm{~m}$. Depending on flight speed, the spatial sampling interval ranged between 0.02 and $0.15 \mathrm{~m}$. Positioning of the profiles was performed by means of a Global Positioning System (GPS).

After eye inspection of the data and the removal of outliers and the low frequency helicopter motion (Hibler 1972, Dierking 1995), the ice morphology is obtained relative to the surface of level ice. With a cut-off height of $0.8 \mathrm{~m}$, pressure ridges are identified by a Rayleigh criterion. By this criterion only local maxima which are 

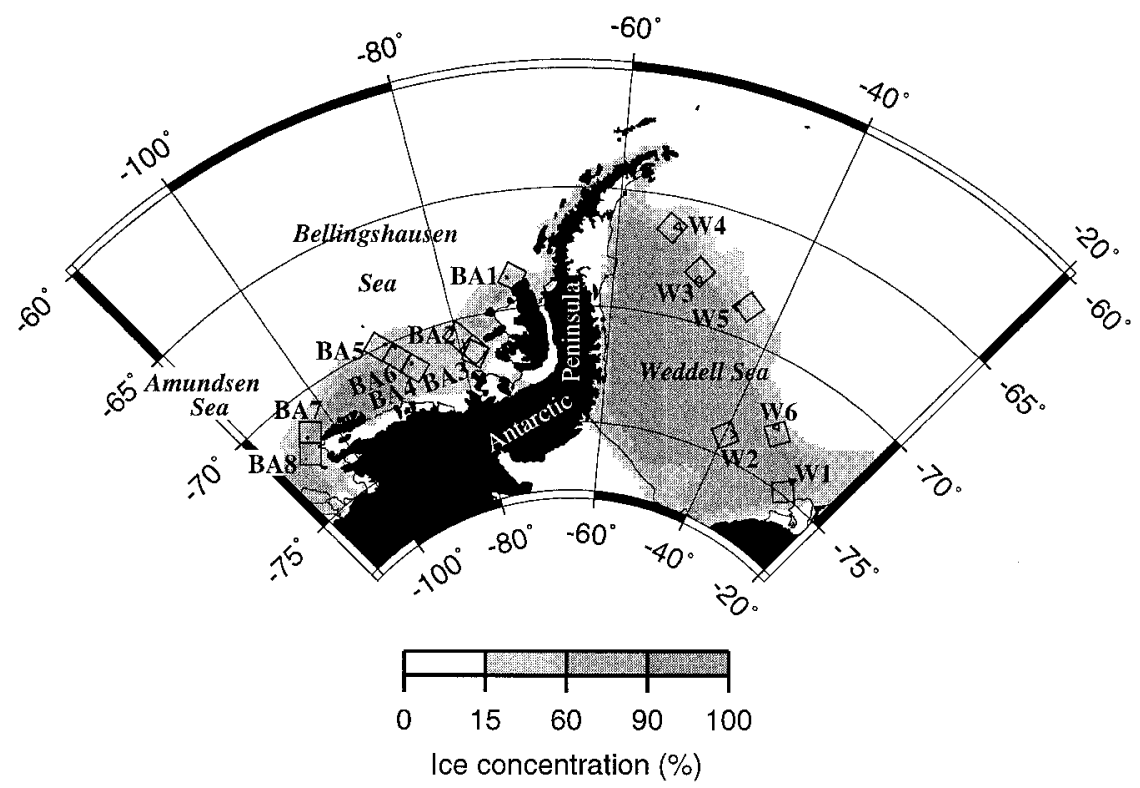

Figure 1. Map of the Bellingshausen/Amundsen (BA) and Weddell Sea, showing the locations of the laser flights and the areas of the corresponding SAR images. The mean ice concentration during February 1994 for the BA Sea and February 1997 for the Weddell Sea are also shown. They have been derived from SSM/I passive microwave data provided by the National Snow and Ice Data Center in Boulder, Colorado.

twice as high as the surrounding local minima are defined as pressure ridges. Consequently broad, multiple ridges are specified as one single feature.

Ridge heights and spacings of Antarctic sea ice have been found to closely form declining exponential distributions (Weeks et al. 1989, Lytle and Ackley 1991, Dierking 1995). The probability density function $p$ for the ridge spacing $s$ is, according to Hibler et al. (1972),

$$
p\left(s ; z_{0}, \mu_{s}\right)=\mu_{s} \exp \left(-s / \mu_{s}\right)
$$

where $z_{0}$ is the sail cut-off height and $\mu_{s}$ is the mean ridge spacing. Here, we restrict ourselves to mean ridge heights and frequencies. The latter are defined as the inverse mean ridge spacings, i.e. the number of ridges per kilometre.

In the Weddell Sea most laser flights were performed close to the ice edge (figure 1). However, only fields with ice concentrations of more than $80 \%$ were profiled (see also figure 2). Open water was not excluded from the data. Therefore, the analysed ridge spacing is enlarged by the areas of open water.

\subsection{Processing of SAR images}

The SAR on ERS1/2 operates at a frequency of $5.3 \mathrm{GHz}$ with a mid-swath incidence angle of $23^{\circ}$. The images cover an area of $100 \mathrm{~km} \times 100 \mathrm{~km}$ with a pixel size of $12.5 \mathrm{~m}$. Values of backscatter $\sigma_{0}$ have been calculated from the signals with an algorithm of Laur et al. (1996). To reduce speckle, $8 \times 8$ pixels were averaged resulting in a pixel size of $100 \mathrm{~m}$.

For the intercomparison of laser and SAR data a statistical approach was chosen 

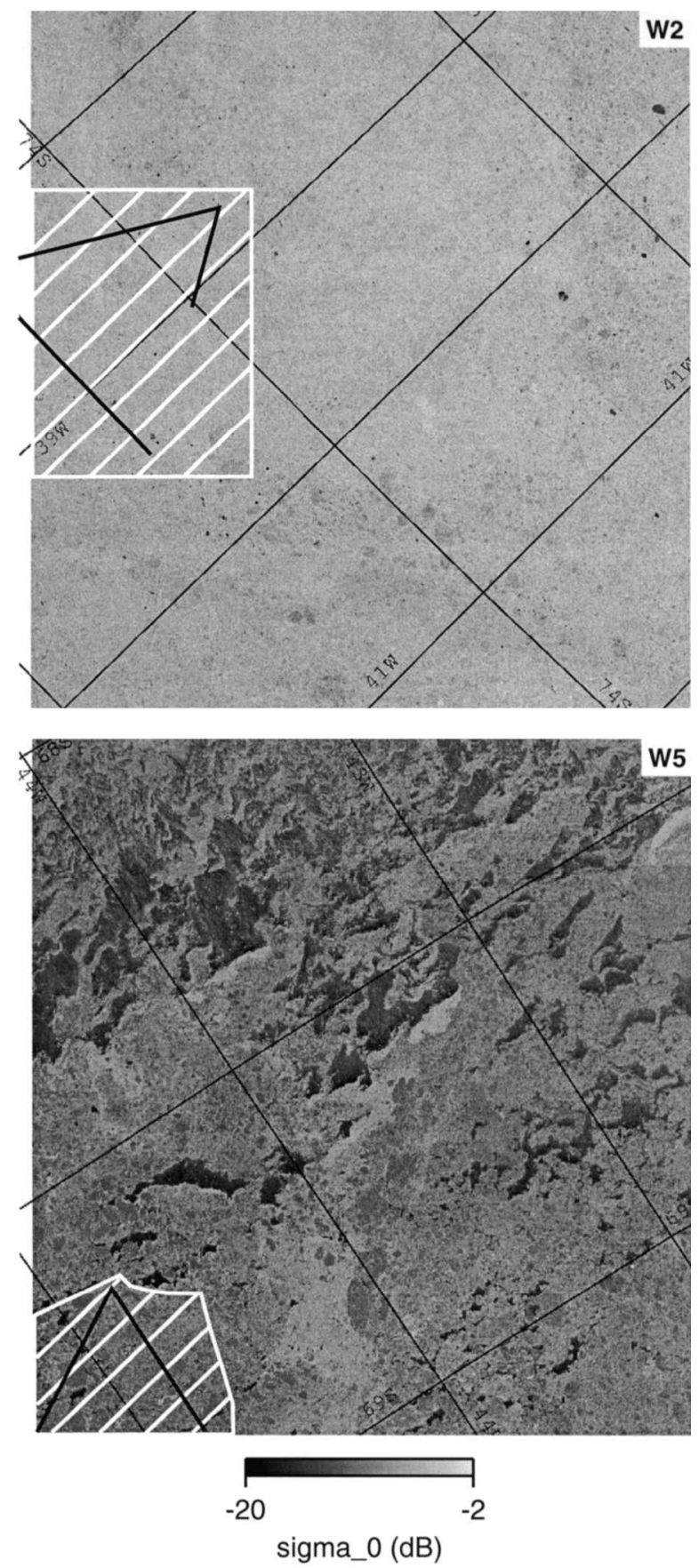

Figure 2. Two $100 \mathrm{~km} \times 100 \mathrm{~km}$ SAR images from the south-east (top, W2) and central (bottom, W5) Weddell Sea (cf. figure 1). Bold black lines indicate the original laser profile track, and white-striped areas indicate the regions for which backscatter distributions (see figure 3) were derived. For comparison, both images have been plotted with the same image enhancement. 
in determining the mean backscatter properties and ridge frequency for an area of about $40 \mathrm{~km} \times 40 \mathrm{~km}$ around the laser profiles (figure 2).

No effort was made to geolocate the SAR images precisely. But based on wind speed, time differences between the SAR overflight and the laser measurements were adjusted by calculating drift speeds of the ice according to Kottmeier and Sellmann (1996), resulting in ice displacements of 4 to $9 \mathrm{~km}$ per day. Even for the Weddell Sea data, where the time differences between SAR and laser measurements were rather large (table 1), a correlation between both datasets is still justifiable. In our analysis, therefore, only homogeneous areas with similar backscatter values were considered, so that a high degree of representativeness of the prevailing conditions was achieved.

For the backscatter values, statistical parameters like the mean, the standard deviation, the skewness and the kurtosis as well as the half width and the tail-tomean ratio (TMR) of the distributions were determined (figure 3 ). The latter is the ratio of the mean backscatter of the upper tail of the distribution and the mean backscatter of the overall distribution. The upper tail was defined as that part of the distribution containing $10 \%$ of the total number of pixel values (figure 3 ). Similä et al. (1992) showed that the TMR is a suitable measure for the number of ridges in a SAR image in so far as the TMR rises with an increasing number of ridges.

\subsection{Neural network}

Since there is no clear relationship between the scatter signal of the SAR and the laser data we propose a neural network to predict pressure ridge frequencies from statistical properties of the SAR images. A neural network is able to treat linear as well as non-linear functions. For our purpose we have applied a layered perceptrontype artificial neural network (Hertz et al. 1991) which has already been successfully applied by Liu et al. (1997) to estimate longwave net radiation from the Special Sensor Microwave/Imager (SSM/I). The network consists of one input layer, one hidden layer, and one output layer. Each layer employs one or more neurons and each neuron in the same layer is connected to the adjacent layer with different

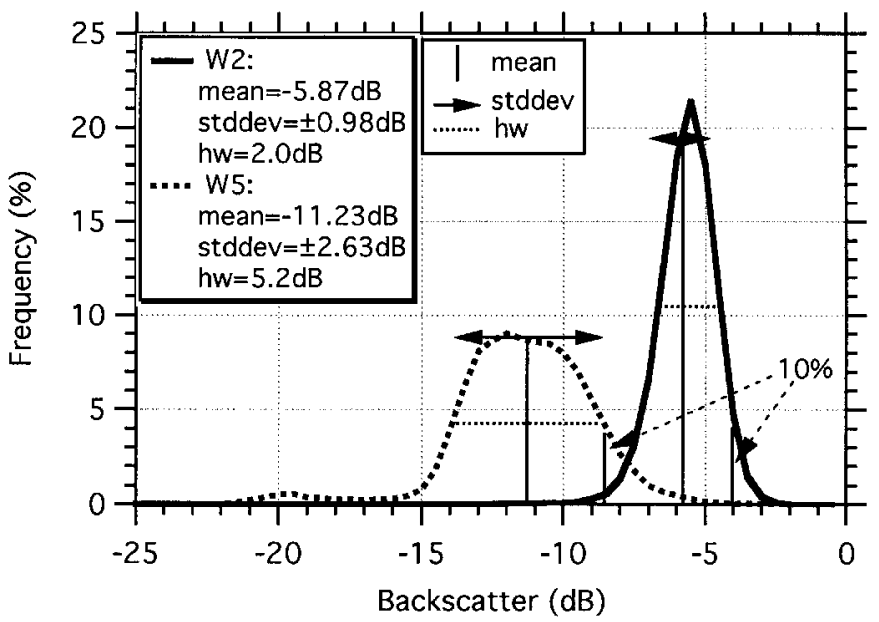

Figure 3. Backscatter distributions of the areas around the laser flights W2 and W5 as indicated in figure 2. The values of the statistical parameters mean, standard deviation (stddev), and half width (hw) extracted from the distributions as well as the upper tail are also given or illustrated. Note the large differences between the distributions. 
weights. The weights can be calculated from a backpropagation learning algorithm based on a training dataset. This backpropagation algorithm uses the gradient descent method to specify a local minimum between the calculated output and the actual output.

The neural network algorithm is trained with the laser and SAR data from the Bellingshausen and Amundsen Seas, and is then applied to the Weddell Sea SAR data.

\section{Results}

The zonal distribution of the mean ridge heights and frequencies from all 14 laser flights is portrayed in figure 4 (cf. the map in figure 1). The correlation between the ridge height and frequency was only 0.58 . The highest ridge frequencies of more than 10 per $\mathrm{km}$ were found in the north-western and south-eastern Weddell Sea. The ice deformation in the central parts of the Weddell and the Bellingshausen Seas was distinctly smaller. In contrast, the number of ridges was high again in the Amundsen and eastern Bellingshausen Seas.
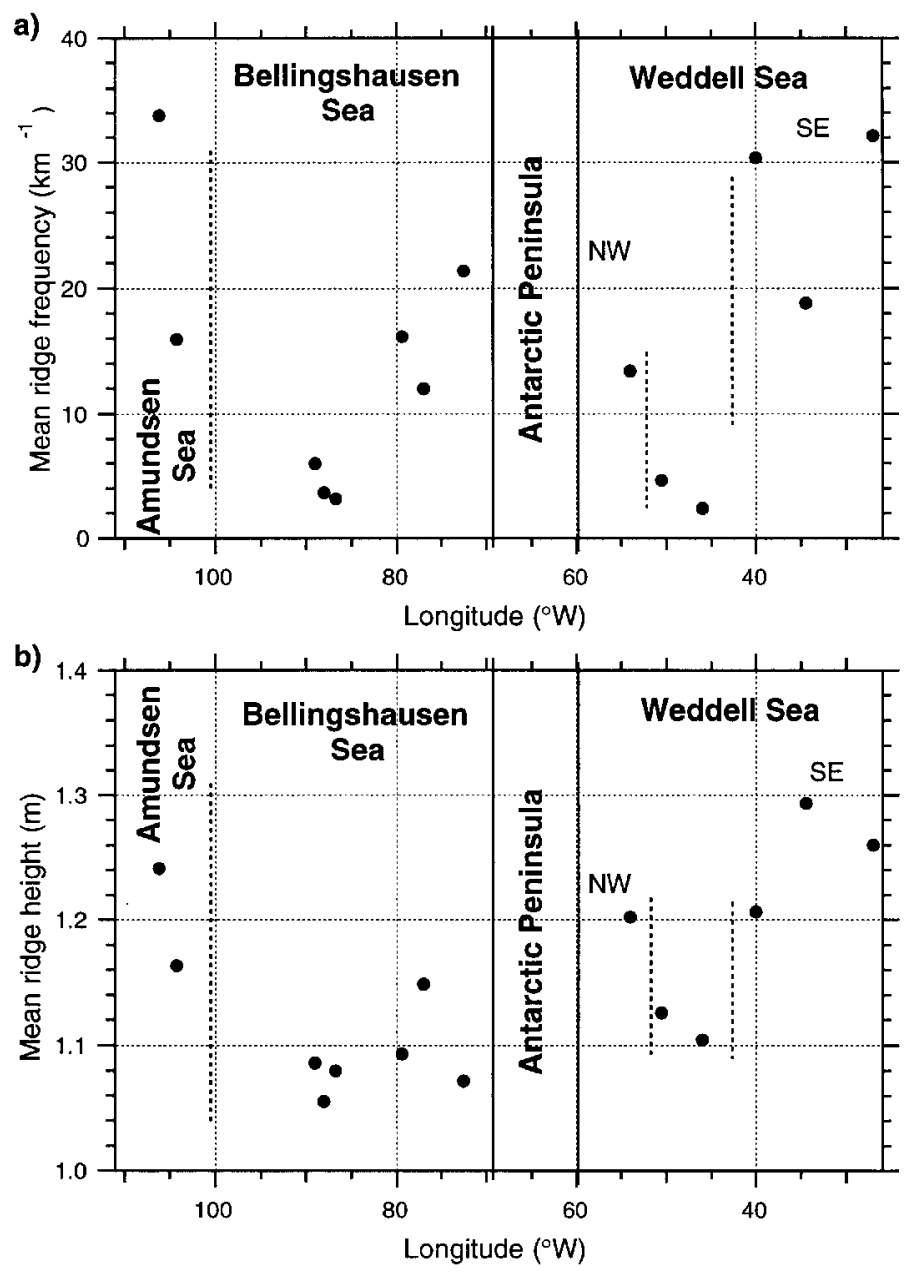

Figure 4. Mean ridge frequencies $(a)$ and heights $(b)$ as derived from all 14 laser profiler flights for a cut-off height of $0.8 \mathrm{~m}$ (cf. figure 1 ). 
The observed patterns clearly reflect increasing ice deformation in coastal areas on the one hand. On the other hand, the age of the ice seems also to play a significant role since the stronger ice deformation in the north-western compared to the central Weddell Sea results, at least to some extent, from the older ice age in the northwestern area where a greater ice thickness prevails too, according to the observations of Lange and Eicken (1991) and Drinkwater and Haas (1994), and to model simulations of Harder and Lemke (1994) and Fischer and Lemke (1994). Larger areas of highly deformed ice in the south-eastern Weddell Sea (flights W1, W2 and W6) were also observed by Granberg and Leppäranta (in press) in 1990 but have not yet been reported from other investigations. In the Amundsen Sea, too, the higher amount of ridging is correlated with a much greater ice thickness if compared with the central Bellingshausen Sea (Haas, 1998).

The main variation of the radar backscatter signal presumably results from ridge frequencies rather than from ridge heights. This conclusion is suggested by the observational fact that ridge heights vary only a little, while the ridge frequencies change distinctly and these changes are reflected in the scatter signal (Similä et al. 1992). Therefore, the subsequent discussion will be restricted to the effects of the mean ridge spacing. In figure 5, several statistical parameters of the SAR backscatter distributions are compared with the laser-derived ridge frequencies. Generally, the correlation obtained is rather poor. Even for the best relationship of the mean backscatter and ridge frequency (figure 5(a)), rms-errors of 40-70\% result between retrieved and measured ridge frequency if the linear regression is used to transform mean backscatter into ridge frequency.

Our data show the weakest correlation between the ridge frequency and the TMR, in contrast to findings of Similä et al. (1992). The reason may be the much higher pixel resolution of their airborne measurements.

Since linear regression does not seem to be adequate to determine ridge statistics from SAR data, an attempt was made to apply the neural network to the data of figure 5. As the dataset from the Bellingshausen and Amundsen Seas has the highest consistency between SAR and laser measurements (table 1), it was chosen as the training dataset. The trained neural network was then applied to the Weddell Sea SAR data (figure 6). The best results were obtained by choosing the mean, the standard deviation and the half width of the backscatter distribution (figure 3, figure $5(a),(b),(e))$ as the training dataset. Differences between the standard deviation and the half width provide a measure of the curvature of the flanks of the distributions.

The mean ridge frequencies retrieved from the SAR images by means of the neural network $f_{S A R}$ are compared with the actual ridge frequencies derived from the in situ laser profiling $f_{\text {Laser }}$ for the Weddell Sea data in figure 6 . The correlation between $f_{S A R}$ and $f_{\text {Laser }}$ amounts to $r=0.93$ and the rms-error between $f_{S A R}$ and $f_{\text {Laser }}$ is 5.3 ridges per $\mathrm{km}$, or $31.4 \%$.

Thus, with this method, improved estimates of ridge frequencies can be retrieved from SAR images. However, an rms-error of about $30 \%$ is still rather high and may not be acceptable for some applications. But further studies may help to improve the neural network and lead to a higher precision of the results.

\section{Discussion}

As many different ice properties contribute to the one-channel SAR signal, none of the relations shown in figure 5 is unique. The neural network, however, can 


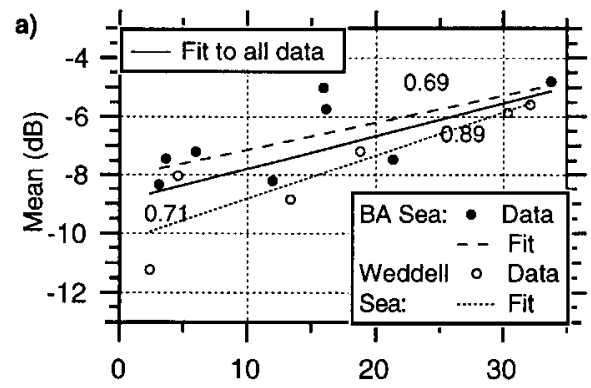

Ridge frequency $\left(\mathrm{km}^{-1}\right)$

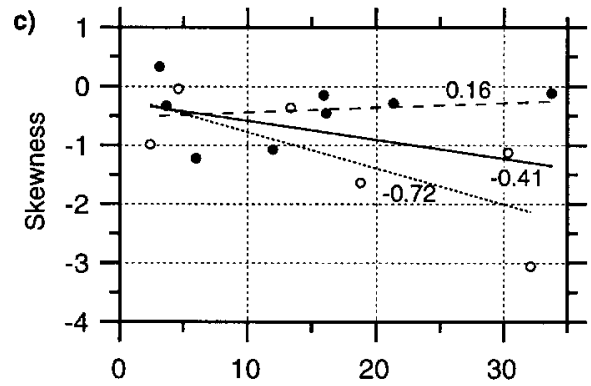

Ridge frequency $\left(\mathrm{km}^{-1}\right)$

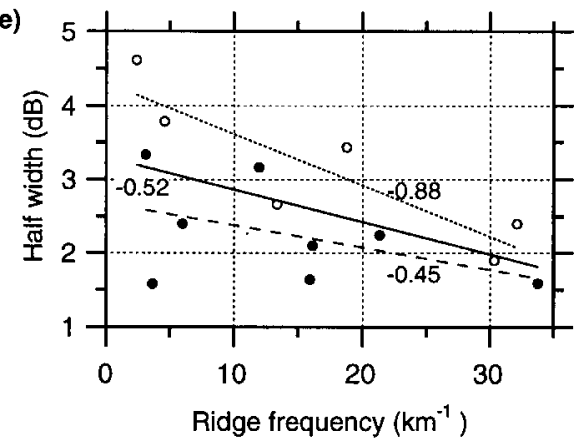

b)

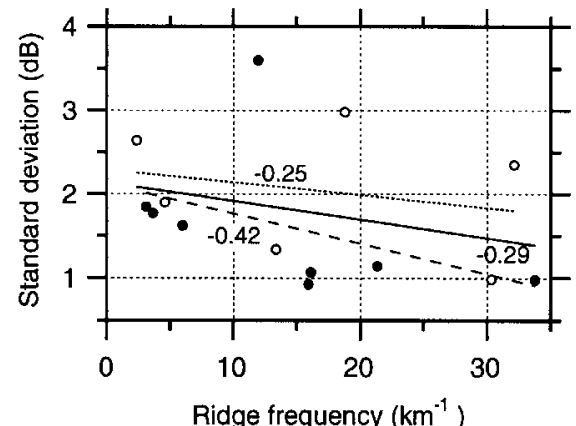

d)

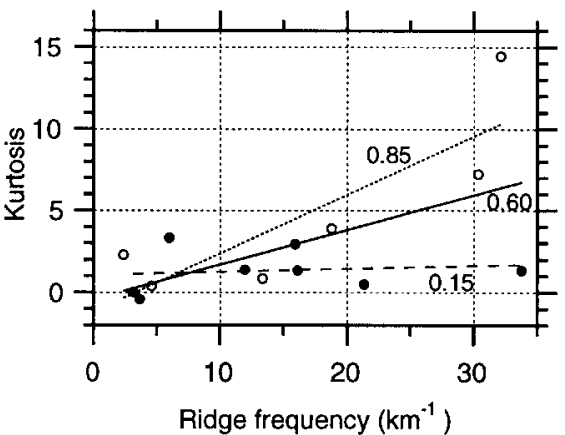

f)

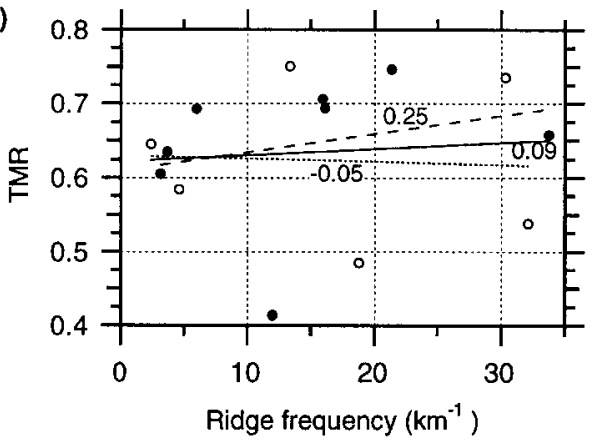

Figure 5. Comparison between statistical properties of the SAR backscatter distributions (cf. figure 3 ) and the laser derived coincident ridge frequency. Mean, standard deviation, skewness, kurtosis, half width and tail-to-mean ratio (TMR) of the distributions are shown for the subscenes from the BA (filled circles) and Weddell Sea (open circles). The lines are linear fits to the data (see legend in $(a)$ ). The correlation coefficients for each fit are given in the figures.

combine all available information to yield a best result in summary. The algorithm seems to be relatively robust with respect to some environmental conditions such as wind roughening of leads. However, advection of warm air masses might affect the backscatter characteristics significantly due to modified ice surface properties (Morris et al. 1998).

It should be noted that our approach is a statistical description of larger areas with sizes of typically $40 \mathrm{~km} \times 40 \mathrm{~km}$. On kilometre scales, ridges are assumed to be more or less homogeneously distributed within these areas, and the SAR signal should not be patchy and should contain no large leads. By our algorithm single 


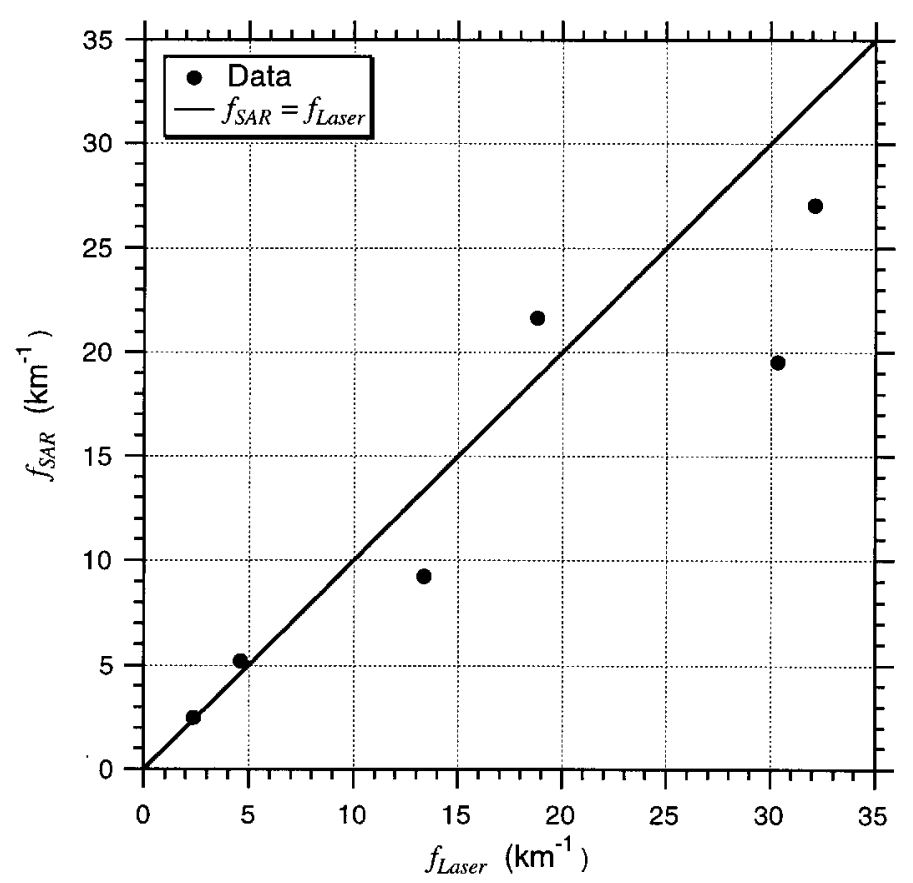

Figure 6. Comparison of ridge frequencies as retrieved from SAR images by means of the neural network and from laser profiling.

ridges or confined ridge zones cannot be resolved; therefore it may best serve to map ridge distributions on a regional scale like the Weddell Sea or similar areas. Our approach is purely empirical so that there is still a strong demand for a proper theoretical model to describe the influence of ridge frequencies on the SAR backscatter signal.

In order to reduce speckle, $8 \times 8$ pixels were averaged, resulting in a pixel size of $100 \mathrm{~m}$. This raises the question of whether the backscatter signal is in fact related to the ridge distribution in spite of the averaging procedure or if other ice properties which might be somehow linked to the ridge frequency contribute primarily to the SAR signal. The mean backscatter, for example, also increases with the frequency of floe edges. In our cases we are not able to discriminate between the ridge and edge effects. Moreover, floe edges are often composed of piled blocks and are then identified as ridges as well. However, the laser measurements indicated smaller floe sizes where the ridge frequency was higher.

The mean backscatter of an area is also influenced by the properties of the level ice. It is difficult to quantify the effect of different material properties like salinity, density, and the presence or absence of flooding (e.g. Drinkwater and Lytle 1997) or melt ponds (Low 1995). However, the laser data enable us to determine the decimetrescale surface roughness of the level ice. Here, the surface slope angle distributions of $0.2 \mathrm{~m}$ long sections or facets of the level ice surface profile are taken as a measure of the decimetre-scale surface roughness. Although the accuracy of the angles is only some degrees due to the nature of the laser data and the subsequent processing (see $\$ 2.1$ ), it is believed to be sufficient to calculate angle distributions for comparison between different flights. As an example, the angle distributions of flights W1-W3 
and W5 (table 1, figure 1) are compiled in figure 7. Only surfaces with elevations below $0.4 \mathrm{~m}$ have been considered as representative for level ice. W1 and $\mathrm{W} 2$ represent regions of a high ridge frequency, whereas $\mathrm{W} 3$ and W5 refer to slightly deformed ice. Flights W1 and W2 indicate a significantly higher percentage of high surface slope angles than flights W3 and W5. In contrast, the fraction of surface facets with slope angles between $0^{\circ}$ and $5^{\circ}$ is highest for W3 and W5. Thus, regions with high ridge frequencies are also marked by a higher roughness of the level ice. This behaviour was observed for all flights. These results indicate that our algorithm might link the mean backscatter to the decimetre-scale roughness of the level ice rather than to the ridge frequency, but that these variables are closely related.

The neural network utilizes not only the mean backscatter, but also the widths of the distributions as expressed by the half width and the standard deviation (figure 3). Obviously, the distributions get wider with decreasing ridge frequency (figure $5(b)$ and $(e)$ ). Due to the negative exponential spacing distribution (equation 1), the probability that $100 \mathrm{~m}$ averaged pixels contain no ridges increases for less deformed ice. Such pixels would possess a rather low backscatter. Therefore, the backscatter distribution for weakly ridged regions is extended towards low values (figure 3). On the other hand, some pixels in these regions may still contain a large number of ridges, as the probability for small ridge spacings is generally highest (equation 1), and ridges principally tend to cluster (Lensu 1995). Therefore, also in weakly deformed regions pixels exist with high backscatter values, such that the upper tail of the backscatter distribution is maintained.

\section{Conclusion}

Spatial ridge frequencies have been determined with the aid of a neural network for areas of several hundred square kilometres from ERS-SAR backscatter signals from Antarctic sea ice in summer. The network was trained with information of SAR backscatter properties and of simultaneous in situ laser profiling data. The retrieved ridge frequencies had a rms-error of about $30 \%$. Although this uncertainty is still high, the algorithm is distinctly superior to methods based on only one backscatter

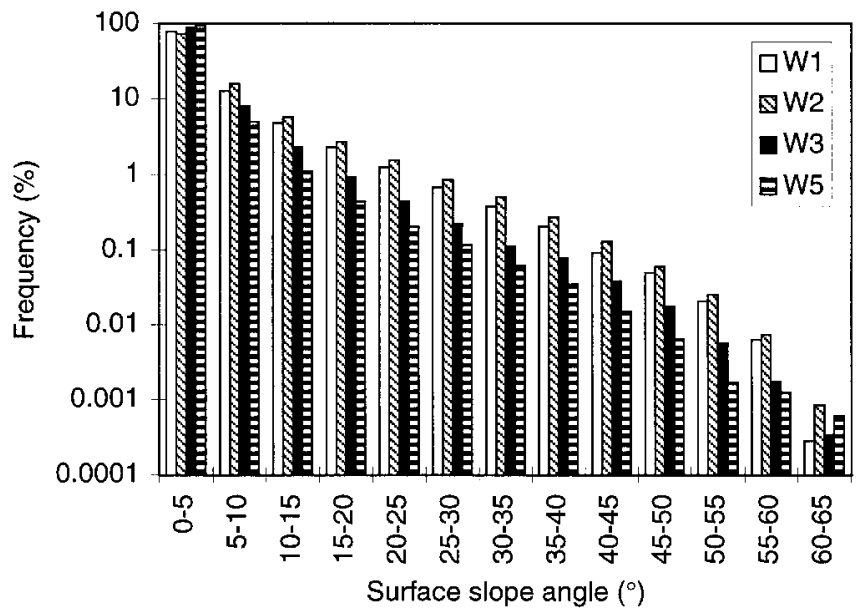

Figure 7. Frequency distributions of surface slope angles of $0.2 \mathrm{~m}$ long sections of the laser derived surface profile from flights W1-W3 and W5. To account for level ice, only surfaces with elevation of less than $0.4 \mathrm{~m}$ have been considered. 
parameter. The utilization of several backscatter properties simultaneously seems to reduce the ambiguities of the results in comparison with the use of a single parameter.

The amount of training and independent in situ data is rather poor, and many more measurements would be required for a final evaluation of the method. However, we believe this to be a promising approach and we suggest further studies under different environmental conditions in the Antarctic as well as in the Arctic.

The application of our algorithm to historic and future ERS-SAR data enables one to compile ridge distributions for the Antarctic pack ice zone as required for the validation of numerical sea-ice models and the compilation of ridging climatologies.

\section{Acknowledgments}

This work is dedicated to the late Thomas Viehoff, who led the laser flight campaign in 1994 and who initiated this investigation. We are grateful to the helicopter pilots and mechanics who enabled us to perform the laser measurements. Jörg Bareiss carefully processed the laser data. The project was funded by the Federal Ministry for Education, Research and Technology in the programme 'Remote sensing of sea-ice properties and processes' (Project no. 03PL018B). The European Space Agency kindly provided the SAR images under the project number AO2-D146-9. This is AWI contribution no. 1626.

\section{References}

Carlström, A., and Ulander, L. M. H., 1995, Validation of backscatter models for level and deformed sea-ice in ERS-1 SAR images. International Journal of Remote Sensing, 16, 3245-3266.

DIERKING, W., 1995, Laser profiling of the ice surface topography during the Winter Weddel Gyre Study 1992. Journal of Geophysical Research, 100, 4807-4820.

DRINK WATER, M. R., 1998, Active microwave remote sensing observations of Weddell Sea ice. In Antarctic Sea Ice: Physical Processes, Interactions and Variability, edited by M. O. Jeffries, Antarctic Research Series, vol. 74 (Washington, DC: American Geophysical Union), pp. 187-212.

DrinK WATER, M. R., and HAAS, C., 1994, Snow, sea-ice, and radar observations during ANT X/4: Summary data report. Reports of the physics department, 53, Alfred Wegener Institute for Polar and Marine Research, Bremerhaven, Germany.

Drink WATER, M. R., and LyTLE, V. I., 1997, ERS-1 SAR and field-observed characteristics of austral fall freeze-up in the Weddell Sea, Antarctica. Journal of Geophysical Research, 102, 12593-12608.

Fischer, H., and Lemke, P., 1994, On the required accuracy of atmospheric forcing fields for driving dynamic-thermodynamic sea ice models. In The Polar Oceans and their Role in Shaping the Global Environment, edited by O. M. Johannessen, R. D. Muench and J. E. Overland, Geophysical Monograph, vol. 85 (Washington, DC: American Geophysical Union), pp. 373-381.

Granberg, H. B., and LePpäranta, M., in press, Observations of sea ice ridging in the Weddell Sea. Journal of Geophysical Research Oceans.

HAAS, C., 1998, Evaluation of ship-based electromagnetic-inductive thickness measurements of summer sea-ice in the Bellingshausen and Amundsen Sea. Cold Regions Science and Technology, 27, 1-16.

Haas, C., Rebhan, H., Thomas, D. N., and Viehoff, T., 1996, Sea ice. In The Expedition ANTARKTIS-XI/3 of RV 'Polarstern' in 1994, edited by H. Miller and H. Grobe, Reports on Polar Research, Bremerhaven, 188/96, pp. 29-43.

Haas, C., Thomas, D. N., Steffens, M., and Bareiss, J., 1998, Physical and biological investigations of sea-ice. In The Expedition ANTARKTIS-XIV of RV 'Polarstern' in 1997, Report of Leg ANT - XIV/3, edited by W. Jokat und H. Oerter, Reports on Polar Research, Bremerhaven, 267/98, pp. 18-30. 
Harder, M., and Lemke, P., 1994, Modelling the extent of sea ice ridging in the Weddell Sea. In The Polar Oceans and their Role in Shaping the Global Environment, edited by O. M. Johannessen, R. D. Muench and J. E. Overland, Geophysical Monograph, vol. 85 (Washington, DC: American Geophysical Union), pp. 187-197.

Hertz, J., Krogh, A., and Palmer, R. G., 1991, Introduction to the Theory of Neural Computation (Reading, MA: Addison-Wesley).

Hibler, W. D. III, 1972, Removal of aircraft altitude variation from laser profiles of the Arctic ice pack. Journal of Geophysical Research, 77, 7190-7195.

Hibler, W. D. III, WeEks W. F., and Mock, S. J., 1972, Statistical aspects of sea ice ridge distributions. Journal of Geophysical Research, 77, 5954-5970.

Johansson, R., and Askne, J., 1987, Modelling of radar backscattering from low-salinity ice with ice ridges. International Journal of Remote Sensing, 8, 1667-1677.

Kottmeier, C., and Sellmann, L., 1996, Atmospheric and oceanic forcing of Weddell Sea ice motion. Journal of Geophysical Research, 101, 20809-20824.

LANGe, M. A., and Eicken, H., 1991, The sea ice thickness distribution in the northwestern Weddell Sea. Journal of Geophysical Research, 96, 4821-4837.

Laur, H. P., Bally, P., Meadows, P. J., Sanchez, J. I., Schaettler, B., and Lopinto, E., 1996, Derivation of the backscattering coefficient $\sigma_{0}$ in ESA ERS-1/2 SAR.PRI products. Technical Note, Issue 2, Rev. 2, ESA-ESRIN.

LEnsu, M., 1995, The analysis of laser profilometer data: AEM flights in the Baltic, winter 1994. M-series report, Helsinki University of Technology, Ship Laboratory, Otaniemi, M-195.

Liu, Q., Simmer, C., and Ruprecht, E., 1997, Estimating longwave net radiation at sea surface from the Special Sensor Microwave/Imager (SSM/I). Journal of Applied Meteorology, 36, 919-930.

Low, D., 1995, The validation of ERS-1 SAR data for Antarctic summer sea ice. MSc thesis, Department of Applied Physics and Electronic and Mechanical Engineering, University of Dundee, UK.

Lytle, V. I., and Ackley, S. F., 1991, Sea ice ridging in the eastern Weddell Sea. Journal of Geophysical Research, 96, 18411-18416.

Manninen, A. T., 1996, Surface morphology and backscattering of ice-ridge sails in the Baltic Sea. Journal of Glaciology, 42, 141-156.

Morris, K., JefFries, M. O., and Li, S., 1998, Sea ice characteristics and seasonal variability of ERS-1 SAR backscatter in the Bellingshausen Sea. In Antarctic Sea Ice: Physical Processes, Interactions and Variability, edited by M. O. Jeffries, Antarctic Research Series, vol. 74 (Washington, DC: American Geophysical Union), pp. 213-242.

Onstott, R. G., 1992, SAR and scatterometer signatures of sea ice. In Microwave Remote Sensing of Sea Ice, edited by F. D. Carsey, Geophysical Monograph, vol. 68 (Washington, DC: American Geophysical Union), pp. 73-104.

Similä, M., Leppäranta, M., Granberg, H. B., and Lewis, J. E., 1992, The relation between SAR imagery and regional sea ice ridging characteristics from BEPERS-88. International Journal of Remote Sensing, 13, 2415-2432.

Steiner, N., Harder, M., and Lemke, P., submitted, Sea Ice Roughness and Drag Coefficients in a Dynamic-Thermodynamic Sea Ice Model for the Arctic Tellus.

Tucker, W. B., Perovich, D. K., Gow, A. J., Weeks, W. F., and Drinkwater, M. R., 1992, Physical properties of sea ice relevant to remote sensing. In Microwave Remote Sensing of Sea Ice, edited by F. D. Carsey, Geophysical Monograph, vol. 68 (Washington, DC: American Geophysical Union), pp. 9-28.

Weeks, W. F., Ackley, S. F., and Govoni, J., 1989, Sea ice ridging in the Ross Sea, Antarctica, as compared with sites in the Arctic. Journal of Geophysical Research, 94, 49844988. 